\title{
A COMPARATIVE STUDY FOR MODIFIED ELECTRO CONVULSIVE THERAPY UNDER GENERAL ANAESTHESIA USING THIOPENTONE, OR ETOMIDATE AS INDUCTION AGENTS ALONG WITH LOW DOSE OF SUCCINYLCHOLINE
}

\author{
Rakesh Chintala Pudi', V. V. Lokeswari², Sai Kishore Mํ, Vijay Kumar Dokala4, Prathima Arasada ${ }^{5}$, Kota Mythili ${ }^{6}$ \\ ${ }^{1}$ Assistant Professor, Department of Anaesthesia, Andhra Medical College, Visakhapatnam, Andhra Pradesh, India. \\ ${ }^{2}$ Assistant Professor, Department of Anaesthesia, Andhra Medical College, Visakhapatnam, Andhra Pradesh, India. \\ 3Junior Resident, Department of Anaesthesia, Andhra Medical College, Visakhapatnam, Andhra Pradesh, India. \\ 4Junior Resident, Department of Anaesthesia, Andhra Medical College, Visakhapatnam, Andhra Pradesh, India. \\ 5Junior Resident, Department of Anaesthesia, Andhra Medical College, Visakhapatnam, Andhra Pradesh, India. \\ 6Junior Resident, Department of Anaesthesia, Andhra Medical College, Visakhapatnam, Andhra Pradesh, India.
}

\section{ABSTRACT}

\section{BACKGROUND}

Modified ECT is a procedure that should be carried out in an anaesthetised person. The essential elements of anaesthesia include rapid loss of consciousness, effective attenuation of the hemodynamic response to the electrical stimulus, avoidance of gross movements, minimal interference with seizure activity and prompt recovery of spontaneous ventilation and consciousness Aims \& Objectives- The aim of the study is to compare the hemodynamic parameters, induction time, seizure duration, recovery time, when using Thiopentone sodium, Etomidate as induction agents in patients undergoing modified elective ECT.

\section{MATERIALS AND METHODS}

This is a prospective randomised control study, conducted in 100 patients of ASA I and II undergoing modified ECT using thiopentone sodium (50) and Etomidate (50) as induction agents. Haemodynamics, induction time, seizure duration, recovery time are recorded at regular intervals.

\section{RESULTS}

Seizure duration is prolonged in Etomidate group compared to Thiopentone group. Induction time and recovery time (R1 return of spontaneous ventilation and R2 able to walk from recovery room) is significantly faster in Etomidate group.

\section{CONCLUSION}

Etomidate is better choice than thiopentone due to rapid and smooth induction, early and smooth recovery. Hence minimum hospitalization is needed for ambulatory patients.

\section{KEY WORDS}

Etomidate, Thiopentone Sodium, Electroconvulsive Therapy (ECT), Seizure Duration.

HOW TO CITE THIS ARTICLE: Pudi RC, Lokeswari VV, Kishore SM et al. A comparative study for modified electro convulsive therapy under general anaesthesia using thiopentone, or etomidate as induction agents along with low dose of succinylcholine. J. Evolution Med. Dent. Sci. 2019;8(07):421-424, DOI: 10.14260/jemds/2019/93

\section{BACKGROUND}

Electro convulsive Therapy (ECT) is a procedure in which electric current is passed through the brain intentionally triggering a brief seizure activity. ECT seems to cause changes in the brain chemistry that can quickly reverse the symptoms of mental illness.

\section{Modified ECT}

The procedure carried out in anaesthetized person. With the use of succinylcholine by Wanderdel in 1951 modified ECT came into existence. Use of general anaesthesia led to the reduced incidence of physical \& psychological trauma. The essential elements of anaesthesia include rapid loss of consciousness, effective attenuation of the hemodynamic response to the electrical stimulus, avoidance of gross

'Financial or Other Competing Interest': None.

Submission 10-10-2017, Peer Review 31-01-2019,

Acceptance 09-02-2019, Published 18-02-2019.

Corresponding Author:

V. V. Lokeswari,

Sri Lakshmi Narsimha Residency,

TF2, Visalakshinagar, Visakhapatnam-43, Andhra Pradesh, India

E-mail: lokikos23@gmail.com

DOI: $10.14260 /$ jemds/2019/93 movements, minimal interference with seizure activity and prompt recovery of spontaneous ventilation and consciousness. ECT plays an important role in treatment of severe and medications resistant schizophrenia, depression, mania, suicidal tendencies, delusional \& catatonic symptoms.

\begin{abstract}
Aims \& Objectives
The aim of this study is to compare the hemodynamic parameters, induction time, seizure duration, recovery time, when using Thiopentone sodium, Etomidate given as induction agents in patients undergoig modified elective ECT.
\end{abstract}

\section{MATERIALS \& METHODS}

This is a prospective randomized controlled study done, after obtaining Institutional Ethics Committee clearance, in Government Hospital for Mental Care Visakhapatnam, comprising of 100 number of patients, who are electively undergoing Modified ECT (Electro Convulsive Therapy), on the orders of Psychiatrist. Duration of study was from March 2016- February 2017. All the 100 Patients were randomized using computer generated random numbers and allocated into two groups, Group $\mathrm{T}$ (Thiopentone), and Group E (Etomidate). 
The actual calculated sample size was 47 in each group by taking time to achieve Modified Aldrete Score of 9 from other published clinical trials (Rohini survey et al), was taken with the effect size 0.7, Mean difference of 5.4 and SD of 7.6 with $70 \%$ power and $95 \%$ confidence interval and 0.05 level of significance. Considering dropouts, unavoidable circumstances in conduction of ECT and to improve the power of study we took the sample size as 100 .

\section{Study Protocol}

Patients belonging to ASA Class I and II, of either sex, electively posted for modified ECT Therapy, between age group 18 years to 60 years are included in the study.

Psychiatric patients, greater than 60 years, children, pregnant women belonging to ASA Grade III and above, Known patients with h/o CVA, Seizure disorders, and Morbid Obese patients, Patients on psychotropic drugs like, Lithium, MAO inhibitors and allied drug are excluded from the study.

A prior pre-anaesthetic check should be done to ensure at least $6 \mathrm{hrs}$ of fasting. Informed (written) consent from the patient and his responsible relatives (or) guardians in a clear, simple \& vernacular language is taken. The procedure room is fully equipped with drugs necessary for cardiopulmonary resuscitation, Intubation, Defibrillation. On arrival into the ECT room intravenous line secured using 18G cannula. The multi Para monitor is connected to the patient to monitor Systolic Blood Pressure (SBP), Diastolic Blood Pressure (DBP), Heart Rate (HR), and Haemoglobin $\mathrm{O}_{2}$ saturation, ECG prior to Induction and throughout the procedure. After starting intravenous line

Pre-anaesthetic medication Inj. Glycopyrrolate $0.2 \mathrm{mg}$ IV before the procedure for Pre-Oxygenation with $100 \% \mathrm{O}_{2}$ for 5 min. Anaesthetic induction with either-

Thiopentone - Dose $2.5 \mathrm{mg} / \mathrm{kg}$

Etomidate - Dose $0.15 \mathrm{mg} / \mathrm{kg}$

The vital parameters are recorded after induction. The blood pressure cuff is applied to the arm needed to be isolated from the effect of muscle relaxation for observing localized seizures, is inflated $100 \mathrm{mg}$ above systolic Blood pressure \& then Inj. Succinylcholine administered in the dose of $0.4 \mathrm{mg} / \mathrm{kg}$ body wt. after isolating the arm by a blood pressure tourniquet. All the patients are ventilated with $100 \% \mathrm{O}_{2}$ till fasciculation subside \& muscle relaxation is achieved. The ECT applied to the head through two electrodes kept at both sides of the Tempero-frontal region (Bi- temporal ECT) after applying ECT gel on the electrodes.

Modified ECT therapy is given using a pulse of $70 \mathrm{~Hz}$ of 1 sec duration with total stimulus not exceeding $1.25 \mathrm{sec}$ by " BPC - 791" Machine for all the patients. A soft mouth gag is inserted inside the oral cavity separating tongue, teeth and buccal mucosa to prevent any damage to the soft tissue of the oral cavity tongue and fracture of teeth during the procedure. After the seizure activity the patients are ventilated with $100 \% \mathrm{O}_{2}$ till regaining spontaneous respiration.

Vital parameters - HR, SBP, DBP, and SPO2 will be recorded.

\section{Duration of Seizure}

Is recorded in seconds from the start of electrical impulse to the end of the clonic contraction using hand held stop watch.

\section{Data Analysis}

The data is entered and analysed in SPSS version 20. Statistical tests done are Unpaired $\mathrm{T}$ test and $\mathrm{P}<0.005$ is taken as significant.

\section{RESULTS}

\begin{tabular}{|c|c|c|}
\hline & $\begin{array}{c}\text { Group T (N=50) } \\
\text { Thiopentone }\end{array}$ & $\begin{array}{c}\text { Group E (N=50) } \\
\text { Etomidate }\end{array}$ \\
\hline Mean Age in Years & 32 & 34 \\
\hline Mean Weight in Kgs. & 59.30 & 61.90 \\
\hline Gender & $23 \mathrm{M} / 27 \mathrm{~F}$ & $28 \mathrm{M} / 22 \mathrm{~F}$ \\
\hline \multicolumn{2}{|c|}{ Table 1. Age \& Weight } \\
\hline
\end{tabular}

In the present study mean age in Group T, Group E were

(32 years ( $T$ ), 34 years (E) respectively.

Mean weight in Group T, Group E (59.3kg (T), 61.9kg(E).

Sex ratio M/F in Group T, Group E (23/27(T), 28/22(E)

\begin{tabular}{|c|c|c|c|c|c|}
\hline $\begin{array}{c}\text { Heart } \\
\text { Rate }\end{array}$ & \multicolumn{2}{|c|}{$\begin{array}{c}\text { Group T } \\
\text { (Thiopentone) } \\
\mathbf{=} \mathbf{5 0}\end{array}$} & \multicolumn{2}{c|}{$\begin{array}{c}\text { Group E } \\
\text { (Etomidate) } \\
\mathbf{= 5 0}\end{array}$} & $\begin{array}{c}\text { P= value } \\
<\mathbf{0 . 0 5} \text { is } \\
\text { Significant }\end{array}$ \\
\hline & Mean & SD & Mean & SD & \\
\hline Pre ECT HR & 98.08 & 14.132 & 101.66 & 14.247 & 0.210 \\
\hline $\begin{array}{c}\text { After } \\
\text { Induction }\end{array}$ & 111.46 & 10.876 & 107.90 & 14.823 & 0.165 \\
\hline ECT 1 min. & 138.62 & 15.292 & 127.46 & 15.111 & 0.000 \\
\hline 3 min. & 141.70 & 15.845 & 137.86 & 15.936 & 0.230 \\
\hline 5 min. & 140.72 & 12.599 & 143.54 & 8.802 & 0.198 \\
\hline 10 min. & 135.42 & 11.978 & 137.18 & 9.550 & 0.419 \\
\hline 15 min. & 128.82 & 10.976 & 130.52 & 8.541 & 0.390 \\
\hline 1 hr. & 122.86 & 7.864 & 124.72 & 8.094 & 0.247 \\
\hline 2 hrs. & 115.50 & 6.795 & 118.66 & 3.978 & 0.006 \\
\hline \multicolumn{5}{|c|}{ Table 2. Heart Rate } \\
\hline
\end{tabular}

In the present study mean heart rate was recorded before induction, after induction and after ECT stimulus. The mean and SD values in Group T, Group E before induction to [98.08 (T), 101.66(E), SD (14.13(T), 19.58(E)] showed no statistical significance.

After induction Ti [(111.46(T), 107.90(E), SD (10.8(T), $15.6(E)$ showed no statistical significance $(\mathrm{p}<0.05)$.

After ECT stimulus at 1-minute T1 [(138.62(T), 127.46(E), SD $(15.29,17.34)]$ showed statistical significance.

T3 [(141.70(T), 137.86(E) SD, (15.84(T), 17.15(E)] showed statistical significance.

T5 (140.72(T), 143.54(E) SD (12.59(T), 15.06(E) showed statistical significance.

T10 (135.42(T), 137.18(E) SD (11.9(T), 11.12(E) showed statistical significance.

T15 (128.82(T), 130.52(E) SD (10.97(T), 11.67(E)) showed statistical significance.

T1hr (122.86(T), 124.72(E), SD (7.86(T), 9.93(E) showed statistical significance.

T2hr (115.50(T), 118.66(E)), SD (6.79(T), 7.07(E)) groups showed statistical significance $(\mathrm{P}<0.05)$.

\begin{tabular}{|c|c|c|c|c|c|}
\hline $\begin{array}{c}\text { Blood } \\
\text { Pressure }\end{array}$ & \multicolumn{2}{|c|}{$\begin{array}{c}\text { Group T } \\
\text { (Thiopentone) } \\
\mathbf{= 5 0}\end{array}$} & \multicolumn{2}{c|}{$\begin{array}{c}\text { Group E } \\
\text { (Etomidate) } \\
\mathbf{= 5 0}\end{array}$} & $\begin{array}{c}\text { p Value } \\
<\mathbf{0 . 0 5} \text { is } \\
\text { Significant }\end{array}$ \\
\hline & Mean & SD & Mean & SD & \\
\hline Pre ECT HR & 118.36 & 7.596 & 113.68 & 9.436 & 0.008 \\
\hline $\begin{array}{c}\text { After } \\
\text { Induction }\end{array}$ & 114.70 & 7.786 & 113.80 & 9.033 & 0.900 \\
\hline ECT 1 min. & 158.74 & 6.739 & 161.72 & 3.004 & 0.006 \\
\hline 3 min. & 158.48 & 6.619 & 161.92 & 3.148 & 0.001 \\
\hline 5 min. & 153.74 & 6.978 & 155.66 & 4.373 & 0.103 \\
\hline
\end{tabular}




\begin{tabular}{|c|c|c|c|c|c|}
\hline 10 min. & 145.54 & 6.609 & 148.74 & 4.159 & 0.005 \\
\hline 15 min. & 137.00 & 6.282 & 139.94 & 4.996 & 0.11 \\
\hline 1 hr. & 128.64 & 4.711 & 130.60 & 4.385 & 0.034 \\
\hline 2 hrs. & 123.78 & 3.158 & 122.84 & 3.28 & 0.940 \\
\hline \multicolumn{6}{|c|}{ Table 3. Mean Systolic Blood Pressure } \\
\hline
\end{tabular}

In the present study mean systolic blood pressure was recorded before induction, after induction and after ECT stimulus. The mean and SD values in the Group T, Group E before induction To [(118.36(T), 113.68(E), SD (7.59(T), 9.43(E)] showed statistical significance, which may be due to variations in systolic blood pressure of individual patients in each group.

After induction Ti [(114.70(T), 113.80(E), SD (7.78(T), 9.03(E)] showed statistical significance.

After ECT stimulus at 1-minute T1 [(158.74(T), 161.72(E) SD (6.73(T), 3.00(E)] showed statistical significance.

T3 (158.48 (T), 161.92(E) SD (6.61(T), 3.14(E)] showed statistical significance.

T5 [(153.74(T), 155.66(E), SD (6.97(T), 4.37(E)] showed statistical significance.

T10 [(145.54 (T), 148.74(E) SD (6.60(T), 4.150(E)] showed statistical significance.

T15 (137.00(T), 139.94(E), SD (6.28(T), 4.99(E)] showed statistical significance.

T1hr [(128.64(T), 130.60(E), SD (4.71(T), 4.38(E)] showed statistical significance $(\mathrm{P}<0.05)$.

T2hr [123.78(T), 122.84(E), SD (3.15(T), 3.28(E)] showed no statistical significance.

\begin{tabular}{|c|c|c|c|c|c|}
\hline & \multicolumn{2}{|c|}{$\begin{array}{c}\text { Group T } \\
\text { (Thiopentone) } \\
=50\end{array}$} & \multicolumn{2}{c|}{$\begin{array}{c}\text { Group P } \\
\text { (Etomidate) } \\
\mathbf{= 5 0}\end{array}$} & $\begin{array}{c}\text { p Value } \\
<\mathbf{0 . 0 5} \text { is } \\
\text { Significant }\end{array}$ \\
\hline & Mean & SD & Mean & SD & \\
\hline $\begin{array}{c}\text { Induction in } \\
\text { Seconds }\end{array}$ & 38.11 & 4.027 & 36.69 & 4.29 & 0.090 \\
\hline $\begin{array}{c}\text { Seizure Duration } \\
\text { in Seconds }\end{array}$ & 34.97 & 6.564 & 43.60 & 10.89 & 0.000 \\
\hline $\begin{array}{c}\text { Recovery of } \\
\text { Spontaneous } \\
\text { Ventilation (R1) }\end{array}$ & 209.96 & 32.115 & 217.34 & 26.782 & 0.215 \\
\hline $\begin{array}{c}\text { Able to Walk } \\
\text { from Recovery } \\
\text { Room (R2) }\end{array}$ & 1453.96 & 188.218 & 1439.02 & 209.42 & 0.702 \\
\hline $\begin{array}{c}\text { Table 4. Induction time, seizure duration \& spontaneous } \\
\text { recovery }\end{array}$ \\
\hline
\end{tabular}

In the present study mean induction time was recorded in all the groups, Group T, Group P, Group E, [(38.11 (T), 36.69 (E), SD [4.02(T), 4.29(E)] showed statistical significance $(\mathrm{P}<0.05)$. the mean induction time was shorter in etomidate group when compared to Thiopentone.

In the present study mean seizure duration was recorded in all the groups, Group T, Group E, [(34.97 (T), 43.60 (E), SD $6.5(\mathrm{~T}), 10.8(\mathrm{E})]$ showed statistical significance $(\mathrm{P}<0.05)$. The mean seizure duration was prolonged in Group $\mathrm{E}$ when compared to Group T

Mean recovery time (R1 and R2) recovery of spontaneous ventilation and able to walk from recovery room in all the Groups, Group T, Group E, R1 [(209.96 (T), 217.34 (E)], SD 32.11(T), 26.78(E)], R2 [(1453.96 (T), 1439.02 (E) SD 188.2(T), 209.2(P), 209.4(E)] showed statistical significance $(\mathrm{P}<0.05)$. The recovery time was shorter in Group $\mathrm{E}$ when compared to Group T.

\section{DISCUSSION}

The present study was undertaken to examine the ideal anaesthetic agents for electro convulsive therapy with the properties of rapid onset of action, short duration of action, with minimal hemodynamic alterations.

The presents study was conducted in 100 number of patients who were divided into 2 groups ie., Group Thiopentone (Group T), Group Etomidate (Group E) each comprising of 50 number of patients in each Group. The dosage of the the drugs were calculated according to the body weight which was adequate to reach the induction criteria i.e., loss of eyelid reflex and could not interfere with ECT induced seizures.

Haemodynamic changes like heart rate (HR) systolic blood pressure (SBP), diastolic blood pressure (DBP) were recorded in all the two groups during pre-induction $\left(\mathrm{T}_{0}\right)$, after induction (Ti), and after applying ECT stimulation (T1) 1 minute (T3)- 3 minutes, (T5)- 5 minutes, (T10) - 10 minutes, (T15)-15 minutes, (T1 Hr)- 1 hour, (T2hr)- 2 hours.

Induction time (IT), seizure duration (SD) was recorded in seconds in all the two groups. Seizure duration was recorded in seconds from the start of electrical impulse to the end of clonic contraction using hand held stop watch. But in the present study only the duration of motor seizure was recorded due to limitations of availability of monitoring devices, seizure duration may be affected by ECT stimulus setting of the machine, to control this all the patients were given ECT stimulus by the same machine with fixed stimulus setting.

Recovery time was recorded in 2 sessions i.e., R1 Recovery of spontaneous ventilation (RSV), R2- able to walk from recovery room (ABWR) in all the three groups in the present study.

Heart rate (HR) was recorded in all the two groups before induction (To), after induction (Ti) and after ECT stimulus. The mean HR in the Group T, Group P and Group E T0 $[(98.08(T), 101.66(E)]$ There was a slight change in the mean heart rate before and after induction in all the two groups. There was a sudden increase in mean heart rate after ECT stimulus in all the two groups for the period of $1 \mathrm{~min}$ to 15 min.

Mean systolic blood pressure (SBP) was recorded in all the two Groups, Group T, Group E before induction ( $\mathrm{T}_{0}$ ), after induction (Ti) and after ECT stimulus. There was an acute increase in the mean systolic blood pressure (SBP) in all the groups after ECT stimulus and was stabilized after 15 minutes of the post ECT recovery period, these findings were in accordance with study of Sonia et al, Rohini et al, Kamath et al. 1

Mean induction time (IT) was record in all the two groups, Group T, Group E were (38.11(T), 36.69(E) seconds. The induction time was recorded in seconds from the start of the administration of the drug to the loss of eyelid reflexes. The mean induction time (IT) was shorter in Group E when compared to Group $\mathrm{T}$ but the induction time was equal in Group T and Group E according to Gupta et al,,$^{2}$ Mehta et al.

Mean seizure duration (SD) was recorded in all the groups Group T and Group E (34.97(T), 43.60(E) seconds). The prolongation of mean SD in the group $\mathrm{E}$ when compared to group $\mathrm{T}$, these findings were in accordance with the study of Conca et al, ${ }^{3}$ Germann et al, Atkins et al,4 Saffer et al. ${ }^{5}$ The 
mean seizure duration for Etomidate was shorter when compared to Thiopentone according to Trazepac et al. ${ }^{6}$

Recovery time was recorded in 2 sessions R1-RSV, R2ABWR in all the three groups. R1 (209.96(T), 217.34 (E) seconds). R2 (1453.96 (T), 1439.02(E) seconds). The mean recovery time in the Group E was shorter when compared to group $\mathrm{T}$ these findings were in accordance with the study of Gupta et al, ${ }^{2}$ Mehta et al, Poonam et al, Carroll et al. ${ }^{7}$

The early recovery time seen with Group E was desirable in outpatient department where patient have to go back to their home after ECT procedure. The shortening of recovery time can save lot of time for the anaesthetist without compromising the safety of the patient. This is very useful now-a-day to minimize hospitalization and in day care procedure.

\section{CONCLUSION}

Present study found that thiopentone in dosage $2.5 \mathrm{mg} / \mathrm{kg}$ and etomidate $0.15 \mathrm{mg} / \mathrm{kg}$, body weight are effective in modified ECT in ASA grade I and II patients. On comparing both the drugs for better induction agent for modified ECT, it is concluded that etomidate is better choice due to rapid and smooth induction, early and smooth recovery and cardiovascular stability. With these conclusions, etomidate is a better choice for modified ECT where minimum hospitalization is needed for ambulatory patient.

\section{REFERENCES}

[1] Rohini S, Bansal S, Sriganesh K, et al. Incidence and risk factors for oxygen desaturation during recovery from modified electroconvulsive therapy: a prospective observational study. J Anaesthesiol Clin Pharmacol 2015;31(1):99-103.
[2] Gupta UK, Mahendru RK, Mehta RK, et al. A comparative study of etomidate and thiopentone in modified ECT. Indian Journal of Psychiatry 1986;28(2):151-4.

[3] Conca A, Germann R, Konig P. Etomidate vs. thiopentone in electroconvulsive therapy. An interdisciplinary challenge for anaesthesiology and psychiatry. Pharmacopsychiatry 2003;36(3):94-7.

[4] Khalid N, Atkins M, Kirov G. The effects of etomidate on seizure duration and electrical stimulus dose in seizure-resistant patients during electroconvulsive therapy. J ECT 2006;22(3):184-8.

[5] Saffer S, Berk M. Anaesthetic induction for electroconvulsive therapy with etomidate is associated with longer seizure duration than thiopentone. J ECT 1998;14(2):89-93.

[6] Trazepacz PT, Weniger FC, Greenhouse J. Etomidate anesthesia increases seizure duration during ECT. A retrospective study. General Hospital Psychiatry 1993;15(2):115-20.

[7] O'Carroll TM, Blogg CE, Hoinville EA, et al. Etomidate in electroconvulsive therapy. Journal of Anaesthesia 1977;32:868-72. 